\title{
Genomics for Public Health Improvement: Relevant International Ethical and Policy Issues around Genome-Wide Association Studies and Biobanks
}

\author{
T. Pang \\ Lee Kuan Yew School of Public Policy, National University of Singapore, Singapore
}

\section{Key Words}

Biobanks · Ethics · Genome-wide associations · Policy

\begin{abstract}
Genome-wide association studies and biobanks are at the forefront of genomics research and possess unprecedented potential to improve public health. However, for public health genomics to ultimately fulfill its potential, technological and scientific advances alone are insufficient. Scientists, ethicists, policy makers, and regulators must work closely together with research participants and communities in order to craft an equitable and just ethical framework, and a sustainable environment for effective policies. Such a framework should be a 'hybrid' form which balances equity and solidarity with entrepreneurship and scientific advances. A good balance between research and policy on one hand, and privacy, protection and trust on the other is the key for public health improvement based on advances in genomics science.
\end{abstract}

Copyright $\odot 2013$ S. Karger AG, Basel

\section{Introduction}

Despite the passage of more than 10 years after the first annotation of the complete sequence of the human genome, and its undeniable impact in accelerating biomed- ical research, many believe that its promise is still to be fulfilled, and the clinical benefits are so far scarce $[1,2]$. While much has been made of the impact of genomics on individual health (e.g. 'personalized medicine'), much less attention has been placed on its impact on the public health and population level [3,4], especially in the developing world. The emphasis has been on genomics 'discovery' research rather than on how such discoveries could be integrated into practice and to evaluate its health impact among all segments of the population. Arguably, cataloguing the enormous range of genomic and phenotypic variation in human populations is fundamental to developing effective interventions at the level of the individual patient.

At the same time, and perhaps reflecting the public's growing interest in maintaining health and participating in health-care choices, an independent advisory group has urged the UK government, for example, to integrate genomic medicine into its National Health Service [5]. The government of Thailand has also embarked on a Thai single nucleotide polymorphism discovery project in order to understand the genomic diversity of its population and utilize this information for improving the efficiency of its health care delivery system [6].

Public health genomics is defined as the responsible and effective translation of genome-based knowledge and technologies for the benefit of population health. A sus-

\begin{tabular}{ll}
\hline KARGER & $\begin{array}{l}\text { ๑ 2013 S. Karger AG, Basel } \\
1662-4246 / 13 / 0162-0069 \$ 38.00 / 0 \quad \text { Karger }\end{array}$ \\
E-Mail karger@karger.com & $\begin{array}{l}\text { This is an Open Access article licensed under the terms of } \\
\text { the Creative Commons Attribution-NonCommercial-No- } \\
\text { www.karger.com/phg }\end{array}$ \\
$\begin{array}{l}\text { Derivs 3.0 License (www.karger.com/OA-license), applica- } \\
\text { ble to the online version of the article only. Distribution for } \\
\text { non-commercial purposes only. }\end{array}$
\end{tabular}

Tikki Pang

Lee Kuan Yew School of Public Policy, National University of Singapore

469C Bukit Timah Road

Singapore 259772 (Singapore)

E-Mail spptep@nus.edu.sg 
tainable and equitable process from genomics research to public health interventions requires well-established ethics standards and policies, especially in developing country settings. Research in this field should not only meet the highest ethical, legal and socially appropriate standards, but must also be accompanied by effective policies to ensure that products and outcomes are, as a minimum, targeting the greatest public health needs and also reach individuals in greatest need.

Modern genomics research presents ethical and policy challenges which are different from traditional approaches in biomedical research. Genome-wide association studies (GWAS) and whole-genome sequencing, in particular, are 2 of the major approaches in genomics research today, which may have important repercussions on public health. GWAS, which scan the genomes of thousands of people for known genetic variants in the form of single nucleotide polymorphisms, have proven highly successful in identifying variants associated with susceptibility to chronic diseases such as Alzheimer's disease, type 2 diabetes and macular degeneration $[7,8]$. It has been reported that more than 300 associations have been made for more than 70 common diseases [9]. At the same time, genomic biobanks are underlying much of modern genomics research. These banks link genomic information with clinical data, health outcomes and other information and are keys to both basic research and to facilitate translation into interventions which will ultimately lead to public health advances.

These advances also highlight the appearance of a 'dual track' in the scientific enterprise, which is based on both an infrastructure science (e.g. biobanks, cloud computing, health databases, etc) and the classic discovery sciences (e.g. cell and molecular biology, proteomics, metabolomics, etc). In this regard, infrastructure science is still underrecognized and underappreciated among scientists and presents a formidable challenge for bioethics as it is based primarily on values such as citizenship, equity, individual rights, and solidarity; whereas classic discovery science is often driven by individual entrepreneurship and personal gain (whether acknowledged openly or not) or personal recognition.

Informed by ethical requirements and needs, appropriate policies must also be developed to ensure that the fruits and benefits of the genomics revolution are effectively applied to population health improvement in the developing world. The ethical and policy issues in these 2 areas will be elaborated in more detail, albeit in a more selective rather than comprehensive fashion.

\section{Ethical Considerations}

With the increasing visibility of GWAS and establishment of biobanks, ethical concerns must be addressed in order to earn trust and develop informed partnerships between researchers and different segments of society. In addition to standard ethical, legal and societal issues associated with biomedical research more generally, public health genomics research poses special challenges in 4 important areas: identifiability, informed consent, selection, and role of participants, and the reporting of results.

Identifiability, in particular, has been a cause of concern, as there is a worry that even small amounts of genome data can be potentially identifying for individuals (thus breaching confidentiality), may not be easy to anonymize [10] and must thus be managed carefully in order to maintain public trust [11]. The challenges around identifiability have increased significantly, as data and information are being collected from ever larger cohorts of participants (by several orders of magnitude) and retrospective analysis is being increasingly carried out.

Informed consent, as understood in the traditional sense, has also become problematic because of the reality that genomic data has the potential to be utilized well beyond the original study [10] and that it is sometimes difficult to predict what future use could be made with collected samples. Biobanks, which collect biospecimens accompanied by data on medical history, behavior and health outcomes, represent special problems around informed consent and many ethicists have argued that traditional informed consent may not be sufficient [12] and that new approaches should be developed which provide for more flexibility and increased participation. For example, a proposal has been made to give donors/participants more say in how the samples are used [13], which is based on more equitable partnerships between biobanks and participants. This approach uses a web portal to permit participants to control the information they provide, see how it is used and what new findings may mean for them [13]. Such innovative approaches will strengthen the public's trust in science and is especially important in the context of developing countries where biobanks are now being increasingly established [14], as exemplified by China's Kadoorie Study of Chronic Disease and the Mexico City Prospective Study.

With regards to selection of participants, an observation has been made that, although more than 1,000 GWAS have been performed, the large majority of the subjects involved are people of European descent [15]. Such a 'sampling bias' could be seen as an ethical issue as limited 
racial and ethnic diversity may have implications for the benefits of such research to accrue to those who are most in need, especially populations living in the developing world [15].

Also, a principle exists whereby there should be transparent and accessible reporting of the results of medical research which, in the case of public health genomics research, poses special challenges in relation to balancing research data access with privacy and protection of study participants [16]. This concern has led to a suggestion for the establishment of a checklist to improve the reporting of genetic association studies, referred to as the STREGA statement (Strengthening the Reporting of Genetic Association Studies) [17].

Other ethical challenges include sample ownership and unpredicted future use of collected samples and the extent to which research projects should support the provision of clinical care for research participants (particularly where those projects involve case discovery).

\section{Policy Issues and Implications}

Informed by adherence to sound ethical principles and concomitant concerns for social justice, appropriate policies must also be developed to ensure that public health benefits from advances in genomics science. Such policies fall into 2 broad categories: policies affecting health care delivery and policies which guide ongoing research in public health genomics.

Introduction of health interventions derived from advances in genomics sciences to improve population health should be based on policies which should take some key issues into consideration. In addition to the obvious issue of cost, this includes population-oriented versus individualized focus, collective welfare versus the welfare of individuals, the risk of exacerbating health disparities and inequities of access, distributive justice, individual privacy versus group rights, protection against genetic discrimination and stigmatization (e.g. by insurance companies), and public deliberation and communication. The latter, in particular, should aim to improve the general knowledge of genomics among communities and develop tools to enhance the understanding, use and acceptance of new products of genomics research by the population. Technical matters aside, gaining public trust and confidence is paramount, as genomics science has been highlighted as having nefarious potential, e.g. in the recent creation of potentially lethal pathogens [18].

Ethical and Policy Issues in Genomics for Public Health
In the research arena, policies are needed, for example, which will: (1) support training of developing country researchers not just in genomic sciences, but in other disciplines such as epidemiology; (2) ensure that research addresses the particular challenges of genomics research in developing country settings, including the balance between discovery-type research and implementation of practical applications derived from genomics science; (3) identify traditional knowledge and cultural practices around which new concepts in genomics can be built for integration into the understanding of developing world populations; (4) support development of guidelines for the regulatory aspects of genomics research and its use; (5) reduce inequities in research efforts and ensure ethical collaboration and equitable data access and sharing, data release and publication, including the vigilance to avoid exploitation from institutions in the more developed countries, and (6) building public trust and confidence in genomics research. Both policy and research priorities need to be defined so that developing world researchers can play leading roles in the generation and translation of knowledge for improving the health of their own populations.

\section{Public Health Genomics and Infectious Diseases}

Against a background of sound ethics and effective policies, it is undeniable that the field of infectious diseases has been well served by genomics research and that technological advances have had a very significant public health impact. These advances have resulted in an unprecedented capacity to rapidly identify emerging and reemerging pathogens. Based on the increasingly huge database of genome sequences of human and animal pathogens, rapid identification has also been accompanied, critically, by the ability to develop rapid diagnostic tests to aid in surveillance and implementation of public health containment measures. The rapid identification of a newly emergent H1N1 influenza virus in 2009 is an excellent example, as is the more recent example identification of a new bunyavirus in China associated with severe fever with thrombocytopenia syndrome (SFTS) [19]. In yet another example, a 'GWAS-like' global network to study the genomic epidemiology of malaria brings together researchers from 21 countries in a unique consortium which hopes to better understand genetic variation as an aid to eliminating the malaria parasite [20]. In the context of the developing world, this approach has a significant potential on the impact of public health.

Public Health Genomics 2013;16:69-72 71 


\section{Future Outlook}

The present review highlights the challenges faced when the ethics of science meets the demands of politics and public policy, and reinforces the reality that the future of genomics must be seen in the context of the key drivers and determinants of health: biological, social and political. Ultimately, and as a necessary tool for future progress, what is needed is a more enlightened 'hybrid' framework of values that strives to combine such values as solidarity and equity with scientific progress and individual entrepreneurship. Such a framework is needed if genomics is to fulfill its potential in relation to its unprecedented predictive, preventive, personalized, and participatory powers.

\section{References}

1 Evans JP, Meslin EM, Marteau TM, Caulfield T: Genomics. Deflating the genomic bubble. Science 2011;331:861-862.

2 The Human Genome Project: 10 years later. Lancet 2010;375:2194.

-3 Merikangas KR, Risch N: Genomic priorities and public health. Science 2003;302:599-601.

$\checkmark 4$ Zimmern RL, Khoury MJ. The impact of genomics on public health practice: the case for change. Public Health Genomics 2012;15: 118-124.

5 Building on our inheritance: genomic technology in health care. A report by the Human Genomics Strategy Group, UK, 2012. http:// www.southampton.ac.uk/cels/407966_ HGSG_Report_PDF\%20for\%20on-line\%20 publication\%20(2).pdf.

6 Séguin B, Hardy BJ, Singer PA, Daar AS: Universal health care, genomic medicine and Thailand: investing in today and tomorrow. Nat Rev Genet 2008;9(suppl 1):S14-S19.

7 Manolio TA, Collins FS, Cox NJ, Goldstein DB, Hindorff LA, Hunter DJ, McCarthy MI, Ramos EM, Cardon LR, Chakravarti A, Cho JH, Guttmacher AE, Kong A, Kruglyak L, Mardis E, Rotimi CN, Slatkin M, Valle D, Whittemore AS, Boehnke M, Clark AG, Eichler EE, Gibson G, Haines JL, Mackay TF, McCarroll SA, Visscher PM: Finding the missing heritability of complex diseases. Nature 2009;461:747-753.
8 McCarthy MI, Abecasis GR, Cardon LR, Goldstein DB, Little J, Ioannidis JP, Hirschhorn JN: Genome-wide association studies for complex traits: consensus, uncertainty and challenges. Nat Rev Genet 2008;9: 356-369.

-9 Donnelly P: Progress and challenges in genome-wide association studies in humans. Nature 2008;456:728-731.

10 Green ED, Guyer MS; National Human Genome Research Institute: Charting a course for genomic medicine from base pairs to bedside. Nature 2011;470: 204-213.

11 Lowrance WW, Collins FS: Ethics. Identifiability in genomic research. Science 2007;317: 600-602.

12 Mitchell RM, Conley JM, Davis AM, Cadigan RJ, Dobson AW, Gladden RQ: Genomics. Genomics, biobanks and the trade-secret model. Science 2011;332:309-310.

13 Saha K, Hurlbut B: Research ethics: treat donors as partners in biobank research. Nature 2011;478:312-313.

14 Sgaier SK, Jha P, Mony P, Kurpad A, Lakshmi V, Kumar R, Ganguly NK: Public health. Biobanks in developing countries: needs and feasibility. Science 2007;318:1074-1075.

15 Bustamante C, Burchard E, De la Vega FM: Genomics for the world. Nature 2011;475: 163-165.
$6 \mathrm{P}^{3} \mathrm{G}$ Consortium, Church G, Heeney C, Hawkins N, de Vries J, Boddington P, Kaye J, Bobrow M, Weir B: Public access to genomewide data: five views on balancing research with privacy and protection. PLoS Genet 5:e1000665.

17 Von Elm E, Moher D, Little J; STREGA collaboration: Reporting genetic association studies: the STREGA statement. Lancet 2009; 374:98-100.

18 Berns KI, Casadevall A, Cohen ML, Ehrlich SA, Enquist LW, Fitch JP, Franz DR, FraserLiggett CM, Grant CM, Imperiale MJ, Kanabrocki J, Keim PS, Lemon SM, Levy SB, Lumpkin JR, Miller JF, Murch R, Nance ME, Osterholm MT, Relman DA, Roth JA, Vidaver AK: Policy: adaptations of avian flu virus are a cause for concern. Nature 2012;482:153154.

19 Yu XJ, Liang MF, Zhang ZY, Liu Y, Li JD, Sun YL, Zhang L, Zhang QF, Popov VL, Li C, Qu J, Li Q, Zhang YP, Hai R, Wu W, Wang Q, Zhan FX, Wang XJ, Kan B, Wang SW, Wan KL, Jing HQ, Lu JX, Yin WW, Zhou H, Guan XH, Liu JF, Bi ZQ, Liu GH, Ren J, Wang H, Zhao Z, Song JD, He JR, Wan T, Zhang JS, Fu $X P$, Sun LN, Dong XP, Feng ZJ, Yang WZ, Hong T, Zhang Y, Walker DH, Wang Y, Li DX: Fever with thrombocytopenia associated with a novel bunyavirus in China. N Engl J Med 2011;364:1523-1532.

20 Malaria Genomic Epidemiology Network: A global network for investigating the genomic epidemiology of malaria. Nature 2008;456: 732-737. 